\title{
A ASSOCIAÇÃO EXTERNA COMO FORMA DE INTEGRAÇÃO DOS PRESÍDIOS ÀS REDES EXTERNAS DO TRÁFICO: A PERCEPÇÃO DOS AGENTES TERRITORIAIS DA SEGURANÇA PÚBLICA NO ESTADO DO PARÁ
}

\author{
Roberto Magno Reis Netto ${ }^{1}$ \\ Clay Anderson Nunes Chagas ${ }^{2}$
}

\begin{abstract}
Resumo: O presente estudo buscou compreender a percepção de atores territoriais da segurança pública do Estado do Pará a respeito do estabelecimento e manutenção de redes e relações junto a agentes sintagmáticos públicos ou privados externos ao cárcere como forma de integração dos presídios às redes territoriais externas do tráfico de drogas. Baseando-se no método hermenêutico e dialético e sob uma abordagem qualitativa e quantitativa, o mesmo se valeu das técnicas de coleta de dados por entrevistas direcionadas a agentes territoriais da segurança no Estado do Pará, seguida de uma análise de conteúdo das falas. Como resultados, identificou-se a utilização da associação à agentes territoriais em liberdade como uma das estratégias de integração do cárcere às redes externas do tráfico, tornando verissímeis, em muito, postulados da literatura. Foram também identificadas informações divergentes da literatura previamente consultada e, principalmente, dados sem referência preliminar um possível envolvimento entre tráfico e milícias no Pará, a vedação à ocorrência de crimes como forma atualmente predominante de relação com as comunidades, causas da presença de favelas no entorno dos presídios e a possibilidade de existência de conivências políticas com as organizações em estudo.
\end{abstract}

Palavras-chave: tráfico de drogas; cárcere; associação à agentes externo; agentes territoriais da segurança pública.

\section{THE EXTERNAL ASSOCIATION AS A FORM OF INTEGRATION OF THE PRESSES TO THE EXTERNAL TRAFFIC NETWORKS: THE PERCEPTION OF TERRITORIAL AGENTS OF PUBLIC SECURITY IN THE STATE OF PARÁ}

\begin{abstract}
The present study sought to understand the perception of territorial actors of public security in the State of Pará with regard to the establishment and maintenance of networks and relations with public or private syntagmatic agents external to the prison as a way of integrating the prisons to the external territorial
\end{abstract}

\footnotetext{
${ }^{1}$ Universidade Federal do Pará. bob_reis_ufpa@yahoo.com.br.

${ }^{2}$ Professor da Universidade do Estado do Pará. claychagas@yahoo.com.br.

Estudos Geográficos, Rio Claro, 16(2): 176-193, jul./dez. $2018 \quad$ (ISSN $1678-698 X)$

http://www.periodicos.rc.biblioteca.unesp.br/index.php/estgeo
} 
networks of trafficking drugs. Based on the hermeneutical and dialectical method and using a qualitative and quantitative approach, data collection techniques were used for interviews with territorial security agents in the State of Pará, followed by an analysis of the contents of the speeches. As a result, the use of the association with territorial free agents was identified as one of the strategies of integration of the prison to the external networks of the trafficking, making very, very, postulates of the literature. Differing information from the previously consulted literature was also identified, and, mainly, data without preliminary reference of a possible involvement between traffic and militias in Pará, the fence to the occurrence of crimes as a predominantly predominant relation with the communities, causes of the presence of favelas in the prisons and the possibility of political acquiescence with the organizations under study.

Keywords: drug trafficking; prison; association to external agents; territorial public security agents.

\section{INTRODUÇÃO}

Em pesquisa desenvolvida junto ao programa de Pós-graduação em Segurança Pública da Universidade Federal do Pará, iniciada a partir de uma revisão literária, seguida de uma atividade inferencial e de categorização, constatouse, sob a teoria de Raffestin (1993), que os agentes territoriais do tráfico de drogas se utilizariam, essencialmente, de seis conjuntos de ações, manejados de forma simultânea e intercruzada (DIAS, 2013) para garantir a integração dos presídios às redes territoriais externas.

As estratégias consistiriam no estabelecimento/manutenção de redes e relações entre os agentes sintagmáticos internos ao cárcere, o estabelecimento/manutenção de relações e cooptação de agentes do sistema penitenciário, a utilização de mediatos para comunicação a partir do cárcere, o estabelecimento/manutenção de redes e relações junto a agentes sintagmáticos públicos ou privados externos ao cárcere, o estabelecimento de redes comerciais internas do tráfico de drogas e, por fim, o enfrentamento direto de agentes sintagmáticos e atingimento símbolos vinculados ao poder público.

Entretanto, como a atividade teórica, ainda assim, dependeria de uma verificação prática das proposições encontradas, essencial ao enfrentamento de problemas relativos ao tráfico de drogas, como a disseminação de facções e das áreas controladas pelo tráfico (AMORIM, 2011; 2015), bem como de uma apontada internacionalização das organizações criminosas brasileiras (ABREU, 2017; DIAS, 2013), o presente estudo se propôs à realização de um esforço empírico voltado à confirmação concreta das hipóteses teóricas, do mesmo modo que uma compreensão de eventuais peculiaridades locais.

Desse modo, se voltando a uma das estratégias destacadas, objetivou-se a análise do seguinte problema: Qual é a percepção de atores territoriais da segurança pública do Estado do Pará a respeito do estabelecimento e manutenção de redes e relações junto a agentes sintagmáticos públicos ou privados externos ao cárcere como forma de integração dos presídios às redes territoriais externas do tráfico?

Estudos Geográficos, $\quad$ Rio $\quad$ Claro, $\quad 16(2)$ : 176-193, jul./dez. $2018 \quad$ (ISSN 1678 -698X) http://www.periodicos.rc.biblioteca.unesp.br/index.php/estgeo 
Pretendeu-se, assim, a análise dos dados teóricos colhidos da literatura, por meio de uma atividade de triangulação (MINAYO, 2002) com as informações obtidas junto àqueles agentes, assim escolhidos por sua proximidade do fenômeno. Nas seções seguintes, serão explanados os postulados teóricos e metodológicos sob os quais esta atividade foi desenvolvida.

\section{DO REFERENCIAL TEÓRICO}

De uma análise crítica do conceito jurídico-legal do crime de tráfico de drogas, concernente à uma série de condutas previstas nos artigos 33, 34, 37 e 38 da lei 11.343/2006 (lei antidrogas), constatou-se que a intenção pragmática do legislador brasileiro consistiria em proibir toda uma cadeia produtiva e comercial de substancias classificadas como entorpecentes, olvidando, no entanto, uma série de questões históricas, políticas e econômicas ligadas a esta vedação (CARVALHO, 2016).

Como afirmou Rodrigues (2004), a proibição do consumo/comércio das drogas, em verdade, estaria diretamente ligada à concentração de monopólios sobre sua utilização nas mãos de grupos econômicos específicos, notadamente, a indústria farmacêutica, sob o disfarce de um discurso sanitário de defesa social que, de outro lado, em nada garantiu o real acesso da população, especialmente a pobre, a meios de provimento da saúde.

Em termos práticos, a complexidade do tráfico de drogas, enquanto fenômeno social, o denotou como uma atividade semelhante à de uma empresa (CHAGAS, 2014), diretamente ligada à questões de demanda/oferta e de controle de áreas comerciais, que se valeria de uma série de estratégias (conjuntos de ações voltadas à dominação de relações de poder) e mediatos (meios, dos mais diversos, utilizados na implementação estratégica) para atingir a finalidade de hegemonia territorial (RAFFESTIN, 1993).

Os agentes territoriais do tráfico de drogas, dessa forma, seriam classificáveis como verdadeiros agentes sintagmáticos atuantes, portanto, conforme planos específicos, que se apropriariam do espaço (dado originário) em busca da implementação de territórios nascidos, justamente, das relações de poder ali existentes (RAFFESTIN, 1993), que, no dizer de Haesbaert (2014) e, superando a lógica estatal, não seriam somente territórios-zona, senão, também, verdadeiros territórios-rede (pontos interligados por diferentes nós no espaço) e territóriossimbólicos, onde a vinculação do agente se dariam muito mais por uma afetividade do que por sua presença física.

Por sua vez, à imagem e semelhança da lógica produtiva mundial, o fenômeno tráfico de drogas se estratificaria, de um lado em oligopólios transnacionais, dificilmente atingidos pelas políticas repressivas da guerra às drogas (RODRIGUES, 2004; D'ÉLIA FILHO, 2014), que articulariam a atividade concentrando lucros no topo e, de outro lado, por meio de grandes contingentes de varejistas, que encontrariam no tráfico uma oportunidade de inserção no mercado e, por sua visibilidade, seriam os alvos principais das políticas de segurança, sofrendo, de forma mais veemente, o processo de superencarceramento (DIAS, 2013) e de desterritorialização precária (HAESBAERT, 2014) decorrente do seu enfrentamento.

Este superencarceramento, no entanto, nem de longe mostrou qualquer contribuição efetiva ao problema: desacompanhado de medidas ressocializantes, a prisão dos agentes territoriais do tráfico de drogas, além de não promover uma

Estudos Geográficos, Rio Claro, 16(2): 176-193, jul./dez. $2018 \quad$ (ISSN 1678-698X) http://www.periodicos.rc.biblioteca.unesp.br/index.php/estgeo 
quebra das redes comerciais preexistentes, aproximou seus atores, instituiu novas relações e, com isso, promoveu o surgimento de facções criminosas no Brasil (DIAS, 2013; AMORIM, 2011, 2015) que adotaram o tráfico, precisamente, como sua principal atividade econômica.

A partir de uma organização inicialmente interna, por sua vez, essas facções se expandiram além das grades dos estabelecimentos prisionais, exatamente, em razão da eficiência das estratégias manejadas por seus agentes territoriais, bem como, em decorrência da falência das políticas estatais relativas ao problema (DIAS, 2013).

Como referido na introdução do estudo, a partir da teoria, foi possível definir seis espécies de estratégias inferidas das ações relatadas por diversos autores, em especial, Dias (2011, 2013, 2014), Dias e Salla (2013) e Dias, Alvares e Salla (2013), Amorim (2011, 2015), Abreu (2017) e Varella (2012, 2015, 2017).

Por sua vez, como subsequente esforço de aprofundamento real em torno do problema, o presente estudo se dignou, como dito, à análise de uma daquelas estratégias: o estabelecimento e manutenção de redes e relações junto a agentes sintagmáticos públicos ou privados externos ao cárcere.

A origem desta estratégia é atribuída a vários fatores. O primeiro, já relatado, diz respeito aos novos nós e tessituras que surgiram nas redes do tráfico de drogas, quando da aproximação de seus agentes territoriais no contexto prisional: a aproximação entre estes, decerto, também teria ocasionado uma aproximação entre associados em liberdade vinculados aos primeiros, originando redes mais complexas do que as inicialmente existentes.

Além disso, com o advento das grandes facções e, com elas, o surgimento de medidas clientelistas (cestas básicas, proteção, contratação de advogados, oferta de gêneros de sobrevivência em geral, etc.) em relação a detentos associados ou não (AMORIM, 2011; 2015; ABREU, 2017; VARELLA, 2017; DIAS, 2013; DIAS; SALA, 2013; MALVASI, 2012a; MALLART, 2014), com certeza, criaram-se mecanismos de fidelização que, quando da libertação destes, garantiria sua adesão por dívida, por retribuição ou, ainda, por constituírem as organizações criminosas uma oportunidade de reinserção social às ações do tráfico de drogas (DIAS, 2013; AMORIM, 2011, 2015; BARCELLOS, 2015).

Com isso, as redes externas passaram a retroalimentar os fluxos de poder decorrentes das redes internas ao cárcere, garantindo a existência vínculos entre agentes encarcerados e o tráfico de drogas extramuros (DIAS, 2013; SAVIANO, 2015).

Dentre outras consequências, restou apontado pela literatura o surgimento de uma capacidade de gestão da violência no âmbito externo, sob auxílio de agentes territoriais em liberdade, que seriam responsáveis pela expansão territorial, imposição de punições e enfrentamentos diretos, conforme decisões tomadas pelas lideranças, geralmente encarceradas, assim como, pela regulação social das comunidades presentes nos territórios das organizações e pela viabilização de fugas, resgates e outras formas de enfrentamento ao poder público (SAVIANO, 2014; AMORIM, 2011, 2015; VARELLA, 2012, 2017, DIAS, 2013; LOURENÇO; ALMEIDA, 2013; CAPITANI, 2012; TEIXEIRA, 2015; DIAS, 2013; MALVASI, 2012a; LUCCA, 2016; TAVARES, 2016; VARELLA, 2017; ABREU, 2017).

Porém, também houve registro sobre interações não violentas com as comunidades onde se encontrariam instalados os agentes do tráfico, sobretudo, quando habitadas por familiares de envolvidos com a atividade: a garantia da lei do

Estudos Geográficos, Rio Claro, 16(2): $\quad 176-193, \quad$ jul./dez. $2018 \quad$ (ISSN 1678 -698X) http://www.periodicos.rc.biblioteca.unesp.br/index.php/estgeo 
silêncio e da aceitação do tráfico em bairros, especialmente os pobres, seria conquistado por meio de medidas clientelistas: distribuição de produtos, como cestas básicas, realização de eventos sociais, pelo custeio de transporte de familiares às cadeias, restauração de áreas, dentre outros, bem como pela oferta de cargos nas organizações e, de maneira especial, pela pacificação de conflitos locais (AMORIM, 2011, 2015; PICANÇO; LOPES, 2016; DIAS, 2013; DIAS; SALLA, 2013; MALVASI, 2012a; MALLART, 2014; VARELLA, 2017), tudo como forma de manter aparatos estatais distantes das áreas de tráfico e, com isso, obter maior liberdade de ação e comércio.

A fidelização das comunidades, inclusive, foi apontada por alguns autores como garantia de sua utilização como trunfos de poder (RAFFESTIN, 1993), como restou registrado em rebeliões paulistas incomumente havidas em horários de visita, onde, mais tarde, se revelou a adesão e participação de parentes que, a princípio, seriam vítimas da ação (DIAS, 2013; AMORIM, 2011, 2015; VARELLA, 2017, LUCCA, 2016).

Por sua vez, a literatura também identificou a participação de profissionais, como advogados, contadores, administradores, etc., e entidades privadas, como igrejas, escritórios etc. na prestação de serviços ao tráfico, como representação jurídica de interesses, administração de contabilidade de atividades ilícitas, dentre outros e, até mesmo, no controle direto de atividades ilícitas das organizações criminosas, promovendo, por exemplo, o fluxo de informações entre encarcerados e o mundo livre ou, até mesmo, inserindo objetos proibidos no cárcere, que, inclusive, teriam setores especializados para sua gestão (DIAS, 2013; MALLART, 2014; AMORIM, 2011; 2015; VARELLA, 2017; ABREU, 2017).

Igualmente, demonstrou a literatura que a estratégia em questão seria viabilizada pela cooptação de agentes públicos envolvidos com o combate ao tráfico, como as Polícias Civil e Militar, Poder Judiciário, Ministério Público, entre outros, para a garantir a não interferência nos negócios das organizações e, até mesmo para obtenção de favorecimentos em flagrantes, investigações e processos judiciais (AMORIM, 2011, 2015; TEIXEIRA, 2015; VAN DUN, 2014; CAMPOS, 2016; DIAS, 2013; ABREU, 2017). Cumpre apenas assinalar, em tempo, que a cooptação de agentes do sistema penitenciário foi uma ação que apresentou peculiaridades tão próprias, que se tornou mais coerente sua classificação como uma estratégia autônoma, como visto ao início, pelo que não é abordada neste estudo, especificamente.

Assim, organizações criminosas que teriam surgido no âmbito dos presídios, e, num segundo momento, se espalhado por zonas pobres das cidades, teriam atingido uma capacidade de expansão territorial que, neste século $X X I$, ultrapassariam as barreiras dos centros urbanos e, até mesmo, do próprio país, encontrando-se registro de sua atuação em outros Estados da América Latina como Colômbia, Bolívia, Argentina, Peru e Paraguai, além de sua relação com grupos armados, máfias e cartéis internacionais (AMORIM, 2015; LOURENÇO; ALMEIDA, 2013; DIAS, 2013).

Com tamanho poderio, apontou a literatura que os grandes grupos de agentes territoriais do tráfico teriam conseguido tecer, por intermédio de suas lideranças encarceradas, até mesmo, acordos políticos com o poder público, em verdadeiras tréguas negociadas nas quais, em troca de uma maior liberdade de atuação no cárcere, as organizações se comprometeriam à cessação de rebeliões, ataques e revoltas, bem como se comprometeriam à preservação de uma paz

Estudos Geográficos, Rio $\quad$ Claro, $\quad$ 16(2): 176-193, jul./dez. $2018 \quad$ (ISSN $1678-698 X)$ http://www.periodicos.rc.biblioteca.unesp.br/index.php/estgeo 
velada, muito interessante, aliás, a certos governos (AMORIM, 2011, 2015; DIAS, 2013; LOURENÇO, ALMEIDA, 2015; TEIXEIRA, 2015; MALLART, 2014; ABREU, 2017).

Nestes termos, constatou-se que a estratégia de estabelecimento de redes e relações junto à agentes externos como importante elemento para integração do cárcere às redes territoriais externas do tráfico de drogas, o que, por sua vez, torna imperiosa a confirmação das proposições teóricas diante da realidade concreta.

Em razão disso, num segundo esforço concreto pela apreensão de dados próximos à realidade, este estudo firmou uma análise, de natureza qualitativa e quantitativa das percepções de agentes vinculados à segurança pública, na mencionada base territorial e tempo presente, como forma de verificação concreta das proposições teóricas, justamente, no sentido de confirmar sua verossimilhança ou não e, ainda, acrescentar especificidades, conforme o caso.

Para tanto, mostrou-se necessária a adoção de um conjunto de técnicas metodológicas específicas e cuidados éticos pertinentes, devidamente explicados na seção a seguir.

\section{DO MÉTODO E TÉCNICAS DE PESQUISA}

Primeiramente, como conjunto procedimental o estudo adotou o método hermenêutico e dialético (STEIN, 1983; HABERMAS, 1987; MINAYO, 2002).

Trata-se de técnica de pesquisa que toma a linguagem como base do conhecimento científico, sem, no entanto, olvidar que esta é influenciável pelo contexto social, econômico, político e histórico em que se inserem os sujeitos envolvidos num estudo, dando origem a uma linguagem sistemicamente perturbada (HABERMAS, 1987), devendo ser analisada, assim, como algo potencialmente alienável.

Para desvelar as influências decorrentes das relações de poder, o método propugna alguns cuidados: a) a consideração dos aspectos históricos dos emissores das informações; b) o respeito à linguagem de cada pesquisado por mais simples que esta seja; e, c) a busca pelo real sentido da informação emitida por cada um. Após esses cuidados, é prudente a realização, ainda, de triangulações internas entre os emissores e externas tanto junto a teoria fundante de um estudo e quanto em face da literatura produzida.

Dessa forma, o método adequou-se perfeitamente à proposta, justamente, por permitir, num primeiro momento, a inferência de informações decorrentes de obras com diferentes objetos de estudo e, num segundo momento, por permitir a análise da visão de um grupo específico de agentes territoriais locais (agentes territoriais da segurança pública), desvelando eventuais distorções decorrentes de seu papel e situação dentro das relações de poder.

Por conseguinte, adotou-se uma abordagem qualitativa focada no conteúdo do discurso dos entrevistados e quantitativa que, reforçando técnicas de análise de discurso, auxiliou na exposição dos resultados do estudo.

Como técnica de pesquisa, utilizou-se a coleta de dados por meio de entrevistas, que, no dizer de Olsen (2015), importa numa interação entre o pesquisador e sujeitos detentores de informações, para apreensão de suas percepções e saberes.

Elaborou-se um protocolo de entrevista (YIN, 2016), com trinta e duas questões semiestruturadas confeccionadas a partir da literatura, controladas pela

Estudos Geográficos, Rio Claro, 16(2): 176-193, jul./dez. $2018 \quad$ (ISSN 1678-698X) http://www.periodicos.rc.biblioteca.unesp.br/index.php/estgeo 
teoria e voltadas à hipótese do estudo (FLICK, 2009), em torno das seis espécies de estratégias mencionadas, cujas repostas foram classificadas, neste trabalho, somente em relação à estratégia de estabelecimento e manutenção de redes e relações junto a agentes sintagmáticos públicos ou privados externos ao cárcere, conforme objetivo primário. As demais estratégias deram origem a outros artigos específicos em razão dos limites da espécie de trabalho.

É de se reafirmar que as estratégias em estudo são manejadas, como constatou Dias (2013), de forma simultânea e intercruzada, pelo que, embora o protocolo tenha delimitado algumas perguntas relativas somente à estratégia acima, observou-se, quando de sua aplicação, a ocorrência de menções sobre a mesma ao longo de toda a fala dos entrevistados. Portanto, para exposição de resultados, valeu-se o estudo da técnica de análise de conteúdo (BARDIN, 2011) para categorização de dados e falas, aproveitando-se uma organização já anteriormente obtida na prévia atividade de revisão literária sobre o tema provocador da presente pesquisa.

A escolha dos entrevistados, por conseguinte, se deu, primeiramente, em razão dos objetivos do programa de Mestrado em Segurança Pública, ao qual o estudo se vinculou, voltado à capacitação profissional e ao desenvolvimento de competências para uma atuação neste campo do conhecimento, o que, obviamente, foi determinante para a escolha de agentes territoriais locais da área da segurança como fonte primária de dados.

Principalmente, a seleção se deu em razão de indicações decorrentes da literatura inicialmente consultada: foram escolhidos entrevistados identificados como diretamente atuantes em órgãos e atividades que, por sua natureza de enfrentamento ao problema ou assessoria, teriam contato efetivo com os agentes territoriais do tráfico e suas respectivas estratégias, sendo, assim, detentores de conhecimentos interessantes ao estudo.

Ainda, conforme recomendado por Yin (2016), houve uma aproximação cuidadosa junto ao campo de pesquisa facilitada pela condição de docentes da área e inteligência e segurança pública, ostentada pelos pesquisadores para verificação das formas de acesso, obstruções a serem removidas e, finalmente, se, de fato, os entrevistados seriam detentores das informações buscadas, após o que, finalmente, restaram definidos os sujeitos da entrevista.

Foram entrevistados desta forma: a) Na Polícia Civil do Estado do Pará PC/PA: O Diretor do Núcleo de Inteligência Policial - NIP - e o Diretor da Delegacia de Narcóticos -DENARC, ambos, delegados em exercício da função no momento da entrevista; b) Na Polícia Militar do Estado do Pará - PM/PA: O comandante do Batalhão de Polícia Penitenciária - BPOP, Oficial em exercício da função no momento da entrevista; c) Na Superintendência do Sistema Penitenciário do Estado do Pará - SUSIPE/PA: O diretor da Assessoria de Segurança Institucional - ASI, oficial da polícia militar no exercício da função no momento da entrevista; d) No Ministério Público do Estado do Pará - MPPA: O Diretor do Grupo de Atuação Especial contra o Crime Organizado - GAECO -, Promotor de Justiça em exercício da função no momento da entrevista; e, finalmente, e) Na Ordem dos Advogados do Brasil, Seção Pará - OAB/PA: o Vice-Presidente da Comissão de Segurança Pública, advogado eleito para a função em exercício no momento da entrevista.

As entrevistas foram realizadas entre o fim do mês de abril/2017 e o início do mês de janeiro/2018, em razão de afastamentos e questões emergenciais ocorridas em algumas das instituições, na sede dos órgãos indicados ou em locais escolhidos

Estudos Geográficos, $\quad$ Rio $\quad$ Claro, $\quad 16(2)$ : 176-193, jul./dez. $2018 \quad$ (ISSN $1678-698 X)$ http://www.periodicos.rc.biblioteca.unesp.br/index.php/estgeo 
pelos entrevistados, em salas reservadas e em horários previamente agendados, justamente para manutenção de uma situação de tranquilidade e controle de interferências, gerando um clima amistoso que permitiu manifestações comprometidas com a proposta apresentada.

Como protocolo ético, o estudo: a) Escolheu somente sujeitos que exerciam funções diretivas, caracterizáveis, assim, como representantes legais autorizados a falar em nome dos órgãos e entidades acima (CARVALHO FILHO, 2013), casos em que as autorizações seriam dadas pelos próprios entrevistados, quando a formalidade foi considerada desnecessária ou, no caso de órgãos subordinados, mediante permissão da autoridade competente; b) As entrevistas foram precedidas da leitura, explicação e subscrição de Termo de Consentimento Livre e Esclarecido TCLE, expositivo da pesquisa, objetivos, vinculação institucional, interesses e riscos e desconfortos, bem como da total garantia do sigilo de identidades e informações.

Como a identificação dos entrevistados, ainda assim, não seria muito dificultosa, garantiu-se que os resultados não fariam qualquer menção a resposta ou visão de entrevistados ou suas instituições, nem tampouco mencionariam unanimidades em relação aos resultados, sempre se utilizando de expressões como opinião majoritária ou visão minoritária, por exemplo, em sua exposição, como forma de respeito ao sigilo das manifestações. Além disso, não serão transcritos trechos das entrevistas, senão, somente termos bem representativos das ideias (redução eidética) que serão destacados em itálico, como outro cuidado tendente à não identificação do dono de cada fala.

Ademais, como dito, as respostas foram transcritas, fragmentadas conforme assuntos específicos inferidos de seu teor e sujeitas a um procedimento de análise de conteúdo (BARDIN, 2011) pelo qual foram organizadas em uma tabela de dupla entrada e submetidas a um processo de categorização, que tomou por base a anterior revisão literária realizada. Como resultados, na seção seguinte, foram expostas as percepções dos agentes da segurança pública entrevistados a respeito das ações utilizadas pelos atores territoriais do tráfico de drogas, notadamente, no que tange à estratégia de estabelecimento e manutenção de redes ou relações entre os agentes sintagmáticos internos ao cárcere.

\section{DOS RESULTADOS E DISCUSSÕES}

\section{BREVE ANÁLISE QUALITATIVA DOS DADOS}

Realizada a atividade de análise de conteúdo das falas dos entrevistados, foram classificados noventa trechos transcritos, relativos às manifestações sobre a estratégia em análise. Seguiu-se, após esta classificação, a uma triangulação dos dados diante dos anteriores achados teóricos, havidos após revisão literária. Desta forma, dos noventa trechos, um quantitativo de setenta e sete se referiam à questões tratadas pela literatura $(85,56 \%$ do total) e treze $(14,44 \%$ do total) apontavam questões sem referência literária anterior.

Por sua vez, dos trechos que encontravam previsão teórica, setenta e três apresentaram concordância com as afirmações dos autores estudados $(81,11 \%)$, ao passo que quatro trechos (aproximadamente $4,45 \%$ do total) apresentaram dados que, a despeito de encontrar referência na literatura, se mostravam divergentes de seus postulados.

Estudos Geográficos, $\quad$ Rio $\quad$ Claro, $\quad 16(2)$ : 176-193, jul./dez. $2018 \quad$ (ISSN $1678-698 X)$ http://www.periodicos.rc.biblioteca.unesp.br/index.php/estgeo 
Esta divisão quantitativa foi tomada por base, por sua vez, para exposição qualitativa dos resultados, dos quais se ocuparam as seções seguintes.

\section{DOS DADOS EM CONFORMIDADE COM A LITERATURA}

Em primeiro lugar, constatou-se que a fala dos entrevistados apresentou concordância majoritária com a literatura (DIAS, 2013; AMORIM, 2011, 2015) quanto à afirmação de que a associação entre internos no cárcere promoveria, também, a união entre suas redes territoriais externas, cuja territorialidade não seria simplesmente quebrada com o encarceramento.

De igual maneira, houve concordância, também majoritária, de que a cooptação de internos pelas facções, mais tarde, os tornaria agentes territoriais externos nas ruas, vinculados àquelas organizações (AMORIM, 2011; 2015; ABREU, 2017; VARELLA, 2017; DIAS, 2013; DIAS; SALA, 2013; MALVASI, 2012a; MALLART, 2014). Porém, embora reconhecida a concessão de benefícios, conforme as falas dos entrevistados, as principais causas dessa fidelização apresentariam divergência em relação à teoria, como se tratou adiante.

Por sua vez, tem-se que a associação dos agentes sintagmáticos do tráfico no cárcere à agentes externos, majoritariamente, foi apontada como responsável pelo sucesso de uma gestão da violência no mundo livre (SAVIANO, 2014; AMORIM, 2011, 2015; VARELLA, 2012, 2017, DIAS, 2013; LOURENÇO; ALMEIDA, 2013; CAPITANI, 2012; TEIXEIRA, 2015; MALVASI, 2012a; LUCCA, 2016; TAVARES, 2016; VARELLA, 2017; ABREU, 2017), especialmente, para fins de controle territorial das áreas de comércio de drogas. Nesse sentido, traficantes, afiliados, contariam com o apoio armado das facções, sob o aval das lideranças encarceradas para fins de manutenção de sua hegemonia territorial por meio da defesa de territórios, cobrança de dívidas, dentre outros, como afirmado por alguns entrevistados.

De igual maneira, a existência de associados externos garantiria a execução de medidas de aplicação das leis do tráfico nas ruas, como a punição de transgressões aos estatutos das organizações e vinganças determinadas pelos agentes encarcerados, bem como de realização de ações colocadas como verdadeiros testes à fidelidade do faccionado, tais quais o enfrentamento ao poder público e seus agentes, em especial, agressões à policiais no âmbito externo às cadeias e auxílio em fugas e resgates e crimes em geral, como assaltos, por exemplo, cujos lucros seriam divididos com as organizações criminosas.

Além disso, também houve menção majoritária sobre uma interação das organizações do tráfico no cárcere junto a parentes de agentes encarcerados, concedendo-lhes, além de proteção pessoal, outros benefícios como pensões, cestas básicas e o custeio de funerais e de transporte para fins de visitação daqueles últimos, inclusive, noutros estados ou municípios, como forma de comprar seu silêncio sobre a organização ou cooptá-los para práticas criminosas, assim como, junto à comunidades de áreas comerciais das organizações criminosas, para fins de garantia do silêncio e conivência destas, confirmando a afirmação de existência destas práticas na literatura (AMORIM, 2011, 2015; PICANÇO; LOPES, 2016; DIAS, 2013; DIAS; SALLA, 2013; MALVASI, 2012a; MALLART, 2014; VARELLA, 2017), embora, presentes algumas divergências mencionadas adiante.

Ainda a respeito da interação com comunidades inerentes às áreas comerciais do tráfico, constatou-se a verossimilhança da informação da concessão

Estudos Geográficos, Rio Claro, 16(2): 176-193, jul./dez. $2018 \quad$ (ISSN 1678-698X) http://www.periodicos.rc.biblioteca.unesp.br/index.php/estgeo 
serviços, mesmo que ilegais à população, como água, gás, televisão à cabo, sobretudo, nas grandes cidades do Sudeste do País. Igualmente, foi apontada pelos entrevistados a utilização da violência como medida de pacificação de conflitos territoriais locais, por óbvio, como meio de afastamento do crime, e, consequentemente, dos órgãos de segurança, deixando o território mais calmo para as atividades inerentes ao comércio de drogas. Entretanto, peculiaridades locais bastante significativas, relativas a este aspecto, foram identificadas e, assim, discutidas adiante.

Por conseguinte, a fala dos entrevistados apontou, majoritariamente, que a vinculação de parentes com o tráfico se daria de uma maneira quase que natural, diante do aprisionamento de um agente territorial da atividade. Embora não fosse descartado o aspecto sentimental, a maioria das falas foi assente em afirmar que a manutenção de um padrão de vida, bem como a necessidade de sustento individual ou familiar seriam as principais razões daquela vinculação.

Nesse sentido, as falas dos entrevistados apresentaram as mesmas divergências literárias em torno do tema. Porém, ainda assim, tornaram verossímil a afirmação literária de que há forte vinculação de parentes com o tráfico de drogas, especialmente, em relação à figura das esposas e companheiras de agentes territoriais do tráfico de drogas.

Outro aspecto encontrado na fala majoritária dos entrevistados, também presente na literatura (DIAS, 2013; MALLART, 2014; AMORIM, 2011; 2015; VARELLA, 2017; ABREU, 2017), diz respeito à associação junto à diversos profissionais privados, contratados para o desenvolvimento de atividades junto às organizações criminosas, conforme planos sintagmáticos das lideranças encarceradas, sendo mencionados advogados, especialmente, além de contadores e administradores e, até mesmo, arquitetos. As menções recaíram significativamente sobre a figura dos advogados, considerando que os mesmos deteriam privilégios relativos as suas inviolabilidades profissionais, que, muitas vezes, seriam utilizadas como facilitadores do acesso às cadeias e, em hipóteses mais graves, como favorecedores para a inserção de drogas e objetos ilícitos, conforme também apontado na teoria.

Além disso, também foi confirmada a existência de setores específicos em algumas facções, notadamente o Primeiro Comando da Capital - PCC, nos mesmos moldes mencionados por Dias (2013), que seriam responsáveis pelo recrutamento de advogados para atuação junto àquelas organizações. Foi mencionada, também, a existência de setores comerciais e contábeis com atribuições específicas.

É interessante afirmar que, inclusive, o discurso de alguns entrevistados, no mesmo sentido de Chagas (2014), foi expresso em comparar a atividade das organizações do tráfico no cárcere e fora dele a uma empresa, sendo assente, em algumas das falas, que o exercício de atividades junto às facções seria encarado, por muitos profissionais, com certa normalidade, como se estivessem exercendo qualquer outro empreendimento comum.

Apontou-se, também, o envolvimento de líderes vinculados a grupos religiosos, o que também foi mencionado na literatura, principalmente, no que tange à concessão aos grupos criminosos, de informações privilegiadas pelas comunidades e exercício da função de pombos-correios das informações das lideranças encarceradas à associados externos.

Por conseguinte, confirmando novamente informações presentes na literatura (AMORIM, 2011, 2015; TEIXEIRA, 2015; VAN DUN, 2014; CAMPOS,

Estudos Geográficos, $\quad$ Rio $\quad$ Claro, $\quad 16(2)$ : 176-193, jul./dez. $2018 \quad$ (ISSN $1678-698 X)$ http://www.periodicos.rc.biblioteca.unesp.br/index.php/estgeo 
2016; DIAS, 2013; ABREU, 2017), houveram menções dos entrevistados a respeito do envolvimento de agentes públicos com as organizações do tráfico, com especial destaque à figura dos agentes penitenciários, que, por suas especificidades, compõem a análise de uma espécie diferenciada de estratégia, no âmbito macro deste estudo, não sendo aqui abordados, portanto, policiais civis e militares e, até mesmo, membros do Poder Judiciário e Ministério Público, embora, quanto a estes últimos, as falas, apesar de majoritárias, tenham sido bastante reservadas em afirmar não ter provas, senão, uma grande crença em razão de fatos evidenciados concretamente.

Este envolvimento, por sua vez, consistiria não só na concessão de informações privilegiadas a respeito de questões interessantes às facções, como indicação dos dias de revistas e intervenções no cárcere, mas, atuações diretamente voltadas as suas atividades, como inserção de bens proibidos e, até mesmo, drogas e armas dentro das cadeias.

Ainda, no que tange ao envolvimento das organizações do tráfico num nível político, nos mesmos termos apontados pela teoria, constatou-se que a fala majoritária dos entrevistados apontou que acordos, realmente, aparentariam ter sido celebrados em contextos de conflito havidos nos Estados do Rio de Janeiro e São Paulo na década passada AMORIM, 2011, 2015; DIAS, 2013; LOURENÇO, ALMEIDA, 2015; TEIXEIRA, 2015; MALLART, 2014; ABREU, 2017), afirmando, no entanto, desconhecer a existência destas práticas no Estado do Pará, ainda que, como foi discutido mais à frente, algumas informações destacadas como elementos não referidos na literatura, pareçam contrariar esta afirmação.

Finalmente, verificou-se a afirmação literária de que os agentes territoriais do tráfico de drogas teriam consubstanciado ramificações por diversos setores da sociedade, o que, o passo, teria lhes permitido uma larga expansão territorial de caráter regional, nacional e, até mesmo, internacional (AMORIM, 2015; LOURENÇO; ALMEIDA, 2013; DIAS, 2013). Mencionou-se, nesse sentido, que o tráfico seria equiparável a um polvo com inúmeros tentáculos, que, à cada prisão, buscaria angariar novos afiliados e redes, utilizando esta técnica para a vinculação de associados externos vinculados aos agentes encarcerados.

Desse modo, as facções de âmbito nacional, de maneira especial, prometeriam apoio à facções legais, incorporando suas redes em troca da autorização para uso de seu nome, bem como em troca da conjugação de redes e proteção territorial, ampliando, à imagem e semelhança de um regime de franquias, o comércio do tráfico de drogas no âmbito nacional e internacional, vinculando-o aos planos das lideranças normalmente encarceradas.

\section{DADOS DISCORDANTES DA LITERATURA}

Por sua vez, embora muitos se tenha confirmado que a fidelização de agentes aprisionados, mais tarde, após a libertação dos detentos, por meios convencionais ou não, garantiria sua associação externa às organizações do cárcere, a fala majoritária dos entrevistados apontou, por outro lado, que no Pará a dívida de drogas firmada ainda nas cadeias seria a principal causa que levaria o agente externo ao cumprimento de ações violentas determinadas pelos agentes territoriais encarcerados. Negou-se, dessa forma, a afirmação literária de que a fidelização se daria, sobretudo, pela adoção de medidas clientelistas oferecidas pelas organizações do tráfico no cárcere.

Estudos Geográficos, Rio Claro, 16(2): 176-193, jul./dez. $2018 \quad$ (ISSN 1678-698X) http://www.periodicos.rc.biblioteca.unesp.br/index.php/estgeo 
Trata-se, possivelmente, de uma realidade identificada em relação ao Estado do Pará, que, além de confirmar a existência de outra estratégia relativa ao comércio dentro do cárcere - tratada em outro trabalho nascido desta mesma pesquisa -, ainda, revelaria que a fidelização das facções, ao menos no âmbito regional, se impõe mais pelo fator medo do que por qualquer outro aspecto ideológico, o que parece insinuar que a forma tradicionalmente simbólica de recrutamento apontada pela literatura em relação às organizações criminosas, ao menos neste Estado, parece não se aplicar.

Além disso, também houve uma negação de afirmações teóricas, novamente em razão de possíveis peculiaridades locais, relativas à dinâmica comercial do tráfico de drogas, no que toca à proibição de comercialização de drogas fora de territórios delimitados pelas facções. Mencionou-se que, no Pará, não haveria uma determinação relativa a quem vender, contrariando a afirmação literária de que áreas comerciais específicas deveriam ser repartidas e severamente respeitadas, senão, apenas indicações de exclusividades relativas aos fornecedores dos produtos do tráfico, que, obrigatoriamente, seriam os agentes territoriais indicados pelas facções, do mesmo modo, aproximando sua atuação, como mencionado acima, a um sistema de franquias.

As razões desta dinâmica, entretanto, permanecem ocultas na fala dos entrevistados, sendo possível presumir, no entanto, que razões comerciais possivelmente estabelecem esse comportamento diferenciado. Em todo caso, tratase de pondo que roga aprofundamento em pesquisas específicas.

\section{DADOS NÃO PREVISTOS NA LITERATURA}

Em relação às informações novas, obtidas na pesquisa, destacou-se, em primeiro lugar, a fala minoritária dos entrevistados no sentido de afirmar que, além de associados comuns, criminosos em liberdade, ex-detentos ou não, vinculados às redes territoriais, no Estado do Pará, haveria o envolvimento de milícias com as organizações do tráfico no cárcere. Embora esta informação possa apresentar relativa discordância com as finalidades e modus operandi relativos aos grupos milicianos nos termos apontados por Cano e Duarte (2014), ainda assim, trata-se de hipótese que não pode ser destacada em relação ao Estado.

Primeiramente, porque mesmo sendo as milícias compostas, até mesmo por reputados agentes da segurança pública, o que, nem de longe, seria garantia de honestidade ou confiabilidade de sua atuação, ainda assim, sua ação não deixa de ser ilegal e abusiva, sendo admissível, portanto, que o tráfico figurasse entre suas atividades. Em segundo lugar, não é inconcebível, numa sociedade de consumo desenfreado (BAUMAN, 1998), que a busca pelo lucro tenha subvertido os propósitos daqueles grupos em sua suposta luta contra o mal, usada como pretexto para extorsão da população, sobretudo, considerando o potencial econômico inerente à atividade de tráfico de drogas.

Em todo caso, trata-se de ponto sobre o qual se recomenda aprofundamento em estudos futuros, sob foco e técnicas metodológicas diferenciadas e cuidados muito específicos, especialmente, considerando que muitas das investigações sobre as milícias no Pará ainda se encontram sob segredo de justiça (fase investigatória), bem como envolvem riscos a serem devidamente calculados pelos pesquisadores.

Por sua vez, outro conjunto de informações inéditas diz respeito à forma de interação entre os agentes territoriais encarcerados e as comunidades locais.

Estudos Geográficos, Rio Claro, 16(2): 176-193, jul./dez. $2018 \quad$ (ISSN 1678-698X) http://www.periodicos.rc.biblioteca.unesp.br/index.php/estgeo 
Apesar de referida pelos entrevistados a existência de áreas que tenham sido objeto de medidas clientelistas em tronca do silêncio e da conivência com o comércio de drogas, tendo sido exemplificado, inclusive, o bairro da Terra Firme, em Belém - PA, relatou-se também que, no Pará, a vedação de roubos e furtos seria a principal forma de interação praticada pelas organizações criminosas na atualidade. Majoritariamente, foi referida a existência de avisos públicos de vedação do cometimento de crimes, disseminados por pichações e mensagens verbais de criminosos locais.

Embora, mais uma vez, se trate de situação que exija estudos específicos, certamente, se pode confirmar a verossimilhança dessas afirmações por meio de registros fotográficos firmados pelos próprios pesquisadores, obtidos de seus contatos presenciais com algumas áreas onde há a identificação do comércio de drogas, como se vê da Figura 01, abaixo.

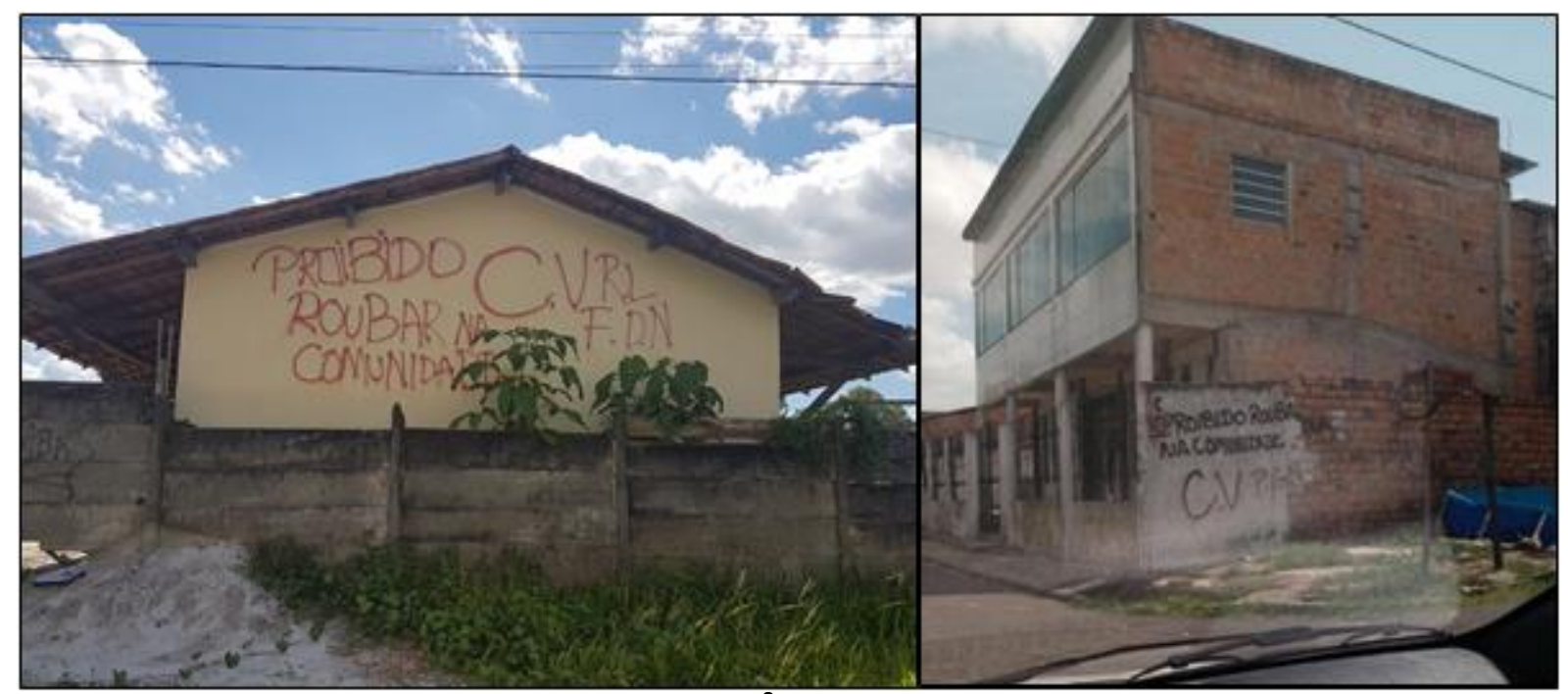

FIGURA 01 - Avisos Públicos (pichações) ${ }^{3}$

Fonte: Acervo dos pesquisadores (2017).

Nota: C.V.R.L. (Comando Vermelho Rogério Lemgruber). C.V. (Comando Vermelho). F.D.N. (Família do Norte). P.G.N. (Primeira Guerrilha do Norte).

Por conseguinte, a fala minoritária dos entrevistados mencionou, em relação à associação de agentes sintagmáticos do cárcere com entidades privadas, que uma pratica nova no Estado e em alguns lugares do Brasil, consistiria no financiamento da criação de Organizações Não Governamentais - ONG's, que atuariam na defesa de direitos de oprimidos, no caso, os encarcerados, mas que, na prática, usariam deste disfarce para obtenção de informações privilegiadas e atuação voltada ao interesse das organizações criminosas.

E, explicando um fenômeno que foi insinuado por Amorim $(2011,2015)$, que comentou que sempre surgiriam favelas próximas aos presídios, encontrou-se, na fala de alguns entrevistados, a explicação de que esses aglomerados (invasões) decorreriam do natural deslocamento de familiares de presos, às vezes, pobres, para as proximidades dos presídios. Contudo, além dessa questão afetiva, tais territórios constituiriam verdadeiros centros de apoio à fugas, bem como de

\footnotetext{
${ }^{3}$ Atribuídos à organizações locais do tráfico vinculadas à facções criminosas, vedando o cometimento de roubos nas comunidades locais, apostos (à esquerda) no muro de uma Escola Pública no bairro do Centro em Santa Bárbara - PA e (à direita) no muro de residência particular no bairro do Mangueirão em Belém-PA, registrados pelos pesquisadores em dezembro de 2017.

Estudos Geográficos, Rio Claro, 16(2): 176-193, jul./dez. $2018 \quad$ (ISSN $1678-698 X)$
} http://www.periodicos.rc.biblioteca.unesp.br/index.php/estgeo 
recepção e transmissão de informações locais privilegiadas por meio de outra estratégia identificada: o uso de mediatos de comunicação com o cárcere, como, por exemplo, detalhes a respeito da chegada nas imediações, de forças policiais ou militares destinadas a realização de revistas e intervenções internas nos presídios.

Conforme se observa na Figura 02 abaixo, essa proximidade entre invasões e presídios, de fato, é uma realidade evidenciada em relação ao principal complexo prisional do Estado, o Americano em Santa Izabel - PA: O presídio, predominantemente situado nos quadrantes inferiores da imagem, tem em seu entorno não só a Vila de Americano, quadrante superior esquerdo, onde são identificadas diversas áreas irregulares, como, também, uma grande invasão situada ás proximidades do complexo, quadrante superior direito.



Figura 02 - Foto via satélite, do Complexo Prisional de Americano e entorno em Santa Izabel do Pará/PA.

Fonte: Google Maps (2018).

Ademais, embora majoritariamente negada a realização de acordos, num nível político, entre as organizações do tráfico e suas lideranças encarceradas com o Poder Público paraense, de outro lado, constatou-se que algumas das falas dos entrevistados sugeriram uma certa conivência com a permanência de líderes de organizações em presídios, onde seu grupo deteria relativa hegemonia, como forma de acalmar as unidades. Igualmente, seria tranquilamente aceito que alguns destes líderes ocupassem funções que permitissem uma maior circulação e contato com seus associados dentro dos presídios, como a de faxineiros, por exemplo.

Esta informação, que certamente é de ciência de membros componentes dos níveis políticos do estado, no mínimo, poderia caracterizar a existência de eventuais acordos tácitos, como forma de manutenção de uma já mencionada paz velada nos presídios, conforme apontado pela teoria em relação a estados do

Estudos Geográficos, Rio Claro, 16(2): 176-193, jul./dez. $2018 \quad$ (ISSN 1678-698X) http://www.periodicos.rc.biblioteca.unesp.br/index.php/estgeo 
sudeste do país (AMORIM, 2011, 2015; DIAS, 2013; LOURENÇO, ALMEIDA, 2015; TEIXEIRA, 2015; MALLART, 2014; ABREU, 2017), o que, por sua vez, seria inédito no Estado.

Em todo caso, as informações mencionadas neste tópico dependem de maiores aprofundamentos em estudos específicos, sob métodos e técnicas voltados às peculiaridades dos casos e sensibilidade de possíveis informações obtidas, o que se recomenda desde logo.

\section{CONSIDERAÇÕES FINAIS}

Ao fim desta análise, deve-se afirmar que a os dados colhidos junto aos agentes territoriais da segurança pública paraense, de fato, confirmaram que a estratégia de estabelecimento e manutenção de redes e relações junto a agentes sintagmáticos públicos ou privados externos ao cárcere propicia o surgimento de vínculos entre o cárcere e as redes territoriais externas do tráfico de drogas.

Além disso, restaram verificadas dissidências entre os dados colhidos e algumas informações teóricas já enunciadas em torno do assunto, principalmente, no que tange à peculiaridades da dinâmica comercial do tráfico no Estado e da utilização do fato medo como principal mecanismo de fidelização de associados externos.

Igualmente, a revelação de dados sem referência literária anterior, como a menção de envolvimento entre organizações do tráfico e milícias no Pará, a predominância da vedação à ocorrência de crimes como forma atual de relação com as comunidades, explicações em torno da presença de favelas nas proximidades dos presídios e a participação de suas comunidades em atividades junto aos agentes territoriais do tráfico no cárcere e, finalmente, a possibilidade de existência de conivências políticas com as organizações em estudo foi identificada ao fim deste estudo, enunciando sua relevância

Deve-se asseverar, ainda, que o conjunto de informações colhidas, além de representar o atingimento do objetivo inicial, traz à baila um conjunto de conhecimentos sensíveis e significantes aos órgãos de segurança pública local e que, nesta perspectiva, devem ser submetidos à posteriores aprofundamentos específicos, o que, de pronto, se recomenda.

Ademais, a partir das falas dos entrevistados, restou comprovada, além da eficácia da estratégia em comento, a efetiva integração dos presídios às redes externas do tráfico de drogas, o que, novamente, ressalta não só a pertinência dos dados colhidos, como, novamente, a necessidade de aprofundamento reflexivo em torno do contexto denunciado.

\section{REFERÊNCIAS}

ABREU, Allan de. Cocaína - A rota caipira: 0 narcotráfico no principal corredor de drogas do Brasil. Rio de Janeiro: Record, 2017.

AMORIM, Carlos. Comando Vermelho: a história do crime organizado. Rio de Janeiro: BestBolso, 2011.

Estudos Geográficos, $\quad$ Rio $\quad$ Claro, $\quad 16(2)$ : 176-193, jul./dez. $2018 \quad$ (ISSN 1678 -698X) 
AMORIM, Carlos. CV - PCC: A irmandade do crime. 13. ed. Rio de Janeiro: Editora Record, 2015.

ARAÚJO, Tarso. Almanaque das Drogas. São Paulo: Leya, 2012.

BARCELLOS, Caco. Abusado: O dono do morro Santa Marta. 26. ed. Rio de Janeiro: Record, 2015.

BARDIN, Laurence. Análise de Conteúdo. São Paulo: Edições 70, 2011.

BAUMAN, Zygmunt. O Mal-estar da Pós-modernidade. Rio de Janeiro: Zahar, 1998.

CAMPOS, Stephanie. The Santa Monica prison and illegal cocaine: a mutual relationship. Crime Law Soc. Change, n. 65, p. 251-268, 2016.

CANO, Ignácio; DUARTE, Thais. Milícias. Crime, Polícia e Justiça no Brasil. São Paulo: Contexto, 2014.

CAPITANI, Rodrigo. O meio ambiente prisional brasileiro e a saúde do preso: um estudo no Presídio Estadual de Bento Gonçalves. Dissertação de mestrado. Rio Grande Do Sul: Universidade de Caxias do Sul, 2012.

CARVALHO FILHO, José dos santos. Manual de Direito Administrativo. 26. ed. São Paulo: Editora Atlas, 2013.

CARVALHO, Salo de. A política Criminal de Drogas no Brasil: Estudo Criminológico e Dogmático da Lei 11.343/06. 8. ed. São Paulo: Saraiva, 2016.

CHAGAS, Clay Anderson Nunes. Geografia, segurança pública e a cartografia dos homicídios na região metropolitana de Belém. Boletim Amazônico de Geografia, v.1, n. 1, p. 186-204, 2014.

CRESWELL, John. Investigação qualitativa e projeto de pesquisa. Porto Alegre: Penso, 2014.

D'ELIA FILHO, Orlando Zaccone. Acionistas do nada: Quem são os traficantes de Drogas. Rio de Janeiro: Revan, 2014.

DIAS, Camila Nunes. Disciplina, controle social e punição: 0 entrecruzamento das redes de poder no espaço prisional. Revista Brasileira de Ciências Sociais, v. 29, n. 85, p. 113-127, 2014

DIAS, Camila Nunes. Estado e PCC em meio às tramas do poder arbitrário nas prisões. Tempo Social, v. 23, n. 2, p. 213-233, 2011.

DIAS, Camila Nunes. PCC: Hegemonia nas Prisões e Monopólio da Violência. São Paulo: Saraiva, 2013.

Estudos Geográficos, $\quad$ Rio $\quad$ Claro, $\quad 16(2)$ : 176-193, jul./dez. $2018 \quad$ (ISSN 1678 698X) http://www.periodicos.rc.biblioteca.unesp.br/index.php/estgeo 
DIAS, Camila Nunes; ALVAREZ, Marcos César; SALLA, Fernando. Das Comissões de Solidariedade ao primeiro Comando da Capital em São Paulo. Revista Tempo Social, v. 25, n. 1, p. 61-82, 2013.

DIAS, Camila Nunes; SALLA, Fernando. Organized Crime in Brazilian Prisons: The Example of the PCC. International Journal of Criminology and Sociology, v. 2, n. 2, p. 397-408, 2013.

FLICK, Uwe. Introdução à pesquisa qualitativa. 3. ed. Porto Alegre: Artmed, 2009.

GOOGLE MAPS (ON LINE). Registro fotográfico do Complexo Prisional de Americano, em Santa Izabel do Pará - PA. Disponível em: < https://www.google.com.br/maps/@-1.2940279,$\underline{48.0528156,3302 \mathrm{a}, 35 \mathrm{y}, 270 \mathrm{~h} / \mathrm{data}=! 3 \mathrm{~m} 1 ! 1 \mathrm{e} 3}>$. Acesso em 10.01.2018.

HABERMAS, Jürgen. Dialética e Hermenêutica: Para a crítica da Hermenêutica de Gadamer. Porto Alegre: LP\&M, 1987.

HAESBAERT, Rogério. Viver no Limite: Território e Multi/Transterritorialidade em tempos de in-segurança e contenção. Rio de Janeiro: Bertrand Brasil, 2014.

LOURENÇO, Luiz Claudio; ALMEIDA, Odilza Lines de. "Quem mantém a ordem, quem cria desordem". Tempo Social, v. 25, n. 1, p. 37-59, 2013.

MALLART, Fábio. Cadeias Dominadas: A fundação CASA, suas dinâmicas e as trajetórias de jovens internos. São Paulo: Terceiro Nome, 2014.

MALVASI, Paulo Artur. Interfaces da Vida Loka: um estudo sobre jovens, tráfico de drogas e violência em São Paulo (Tese). São Paulo: USP, 2012a.

MINAYO, Maria Cecília de Souza. Hermenêutica-Dialética como Caminho do Pensamento Social. In: MINAYO, Maria Cecília de Souza. Caminhos do Pensamento: epistemologia e método. Rio de Janeiro: Editora Fiocruz, 2002.

MINAYO, Maria Cecília de Souza. Introdução: conceito de avaliação por triangulação de Métodos. In: MINAYO, Maria Cecília de Souza; ASSIS, Simone Gonçalves de; SOUZA, Edinilsa Ramos de. Avaliação por Triangulação de Métodos: abordagem de programas sociais. 20. ed. Rio de Janeiro: Editora Fiocruz, 2005.

OLIVEIRA, Giovanni França; COSTA, Gustavo Villela Lima. Revista de Ciências Sociais da Universidade Federal do Mato Grosso do Sul, v. 11, n. 11, p. 2-24, 2012.

OLSEN, Wendy. Coleta de Dados: Debates e métodos fundamentais em pesquisa social. Porto Alegre: Penso, 2015.

PICANÇO, Felícia Silva; LOPES, Natânia de Oliveira. 0 tráfico de drogas em formas: notas de pesquisas sobre o Rio de Janeiro. Análise Social, v. 1, n. 218, p. 96-120, 2016.

Estudos Geográficos, Rio Claro, 16(2): 176-193, jul./dez. $2018 \quad$ (ISSN 1678-698X) http://www.periodicos.rc.biblioteca.unesp.br/index.php/estgeo 
QUEIROZ, Nana. Presos que Menstruam: A brutal vida das mulheres - tratadas como homens - nas prisões brasileiras. 5. ed. Rio de Janeiro: Editora Record, 2016.

RAFFESTIN, Claude. Por uma Geografia do Poder. São Paulo: Ática, 1993.

RODRIGUES, Thiago. Política e Drogas nas Américas. São Paulo: EDUC/FAPESP, 2004.

SAVIANO, Roberto. Gomorra: a história real de um jornalista infiltrado na violenta máfia napolitana. 10. ed. Rio de Janeiro: Bertrand Brasil, 2015.

SAVIANO, Roberto. Zero, Zero, Zero. São Paulo: Companhia das Letras, 2014.

STEIN, Ernildo. Dialética e Hermenêutica: Uma controvérsia sobre o método em filosofia. Síntese, v.1, n. 29, p. 21-48, 1983.

VAN DUN, MIRELA. Exploring Narcosovereignty/violence: Analyzing Illegal Networks, Crime, Violence, and Legitimation in a Peruvian Cocaine Enclave. Journal of Contemporary Ethnography, v. 43, n. 4, p. 395-418, 2014.

VARELLA, Drauzio. Carcereiros. São Paulo: Companhia das Letras, 2012.

VARELLA, Drauzio. Estação Carandirú. 2 Ed. São Paulo: Companhia das Letras, 2015.

VARELLA, Drauzio. Prisioneiras. São Paulo: Companhia das Letras, 2017.

TEIXEIRA, Alessandra. Construir a delinquência, articular a criminalidade: um estudo sobre a gestão dos ilegalismos na cidade de São Paulo (Tese). São Paulo: USP, 2015.

YIN, Robert. Pesquisa Qualitativa: Do início ao fim. Porto Alegre: Penso, 2016.

Artigo submetido em: 30/01/2018

Aceito para publicação em: 06/11/2018

Publicado em: 14/12/2018

Estudos Geográficos, Rio $\quad$ Claro, $\quad$ 16(2): $\quad 176-193, \quad$ jul./dez. $2018 \quad$ (ISSN $1678-698 X)$ http://www.periodicos.rc.biblioteca.unesp.br/index.php/estgeo 